\title{
CARACTERÍSTICAS CLÍNICAS E LABORATORIAIS DE 62 CASOS DE MENINGOENCEFALITE TUBERCULOSA .
}

\author{
CEUCI NUNES*, IRENIO GOMES**, ADELCI TAVARES*, AILTON MELO**
}

RESUMO - Meningite tuberculosa se constitui em uma patologia endêmica há vários anos em várias cidades de países em desenvolvimento. Em Salvador foram estudados 62 pacientes com diagnóstico comprovado de meningoencefalite tuberculosa. A idade dos pacientes variou de 2 meses a 50 anos, $59,7 \%$ dos casos se encontravam na faixa etária inferior a 4 anos. O tempo de doença antes do diagnóstico variou de horas a 90 dias, com média de 13 dias. Os sinais e sintomas clínicos mais comuns foram febre $(86,7 \%)$ e rigidez de nuca $(81,8 \%)$. O exame de líquido cefalorraquidiano mostrou: em média celularidade de $406 / \mathrm{mm}^{3}$ (4 a 1509 ), glicose de $37,3 \mathrm{mg} / \mathrm{dL}$ ( 20 a 70 ) e proteinas de $203 \mathrm{mg} / \mathrm{dL}$ ( 30 a 500 ); predominância de linfócitos foi observada na maioria dos casos, mas em $21,3 \%$ havia mais que $50 \%$ de polimorfonucleares.

PALAVRAS CHAVE: meningoencefalite tuberculosa, meningite tuberculosa, tuberculose do sistema nervoso central, neurotuberculose, tuberculose extra-pulmonar, tuberculose.

\section{Clinical and laboratory characteristics of 62 tuberculous meningoencephalitis cases}

ABSTRACT - The authors present clinical, demographic and laboratory characteristics of 62 patients with proven tuberculous meningoencephalitis admitted at Couto Maia Hospital, reference for patients with infectious diseases in the State of Bahia. The patients' age varied from 2 months to 50 years, $59.7 \%$ of the cases with ages ranging from 0 to 4 years, no sex predominance. The time length for the disease varied from 0 to 90 days, average around 13 days. The most common signs and symptoms were fever and neck stiffness in 86.7 and $81.8 \%$ of the cases respectively. The cerebrospinal fluid showed cells varying from 4 to $1549 / \mathrm{mm}^{3}$, average of 406; glucose from 20 to $70 \mathrm{mg} / \mathrm{dL}$, average of 37.3 , protein from 30 to $500 \mathrm{mg} / \mathrm{dL}$, average of 203 ; lymphocyte predominance occurred in most cases, however in $21.3 \%$ there was predominance of neutrophils.

KEY WORDS; tuberculous meningoencephalitis, tuberculous meningitis, central nervous system tuberculosis, neurotuberculosis, extrapulmonary tuberculosis, tuberculosis.

A tuberculose pulmonar é problema de saúde pública em todo o mundo. Estima-se que em 1990, 8 milhðes de pessoas foram acometidas por esta doença, de 2,6 a 2,9 milhões morrendo ${ }^{3}$. aumento do número de casos dessa patologia está sendo descrito até mesmo em países desenvolvidos, a exemplo dos EUA, assim como epidemias de formas resistentes, relacionadas principalmente a AIDS $^{5}$. Segundo dados da OMS a maior prevalência de tuberculose localiza-se no oeste do Pacífico seguido da África e China. Nas Américas, excetuando-se os Estados Unidos e Canadá, a prevalência de tuberculose em geral é de 25,9\%. No Brasil, em 1990 foram notificados 74570 casos com taxa de incidência de $50,8 / 100000^{3}$.

Entre as formas extrapulmonares de tuberculose a meningoencefalite é considerada a mais grave e correlaciona-se com a incidência da forma pulmonar bacilifera e consequentemente com o

*Hospital Couto Maia; *"Universidade Federal da Bahia (UFBA). Aceite: 12-fevereiro-1996. 
risco de infeccão tuberculosa ${ }^{1,2}$. Estima-se que para países com incidência anual de 45/100000 baciliferos, o risco de infeccão corresponde a $0,75 \%$, com incidência de meningite tuberculosa na faixa etária de 0 a 4 anos, de 4/100000'. Em 1993 no Estado da Bahia, segundo dados da Secretaria Estadual de Saúde, foram notificados 4570 casos de tuberculose pulmonar bacilifera, com coeficiente de incidência de 37,2/100000, 64 casos de meningoencefalite tuberculosa com coeficiente de incidência de 0,5/100000. Esta última manifestação de tuberculose apresenta alta taxa de letalidade, $20 \%$ sendo descrita em menores de 5 anos e $60 \%$ em maiores de 50 anos ${ }^{6}$. No Brasil em 1983, numa pesquisa operacional sobre meningoencefalite tuberculosa promovida pelo Ministério da Saúde, a taxa de letalidade na faixa etária de $0-4$ anos foi $44,7 \%$ ". Entre os pacientes sobreviventes observase elevada taxa de sequelas e elevado tempo de permanência hospitalar ${ }^{11,19}$.

Existe unanimidade entre os autores quanto à dificuldade para se estabelecer um diagnóstico etiológico para a meningoencefalite tuberculosa ${ }^{15,16}$. A positividade da pesquisa de bacilos álcool ácidos resistentes (BAAR) varia na literatura, a maioria dos pesquisadores referindo uma faixa entre $10 \mathrm{a} 40 \%{ }^{21}$. A cultura é uma forma importante de confirmação diagnóstica porém com o inconveniente da demora do resultado?. Técnicas imunológicas têm sido cada vez mais utilizadas devido à rapidez dos seus resultados ${ }^{14}$. Neste estudo incluímos como uma das formas de confirmação diagnóstica o PCR (polymerase chain reaction). Esta técnica, embora não utilizada universalmente, apresenta a grande vantagem da rapidez do resultado. A sensibilidade e especificidade deste método têm variado na literatura e são poucas as referências sobre sua utilização para o diagnóstico da tuberculose no líquido cefalorraquidiano (LCR). Entretanto, nos trabalhos avaliados existe referência de $\mathbf{8 3 \%}$ de sensibilidade e $100 \%$ de especificidade; valores de $70 \%$ e $100 \%$, respectivamente, foram encontrados por Machado e col, em nosso meio ${ }^{10,21}$.

Apresentamos o resultado de estudo sobre a meningoencefalite tuberculosa efetuado em hospital de referência para doença infecto-contagiosas para o Estado da Bahia, o Hospital Couto Maia em Salvador.

\section{MATERIAL E MÉTODOS}

Os pacientes deste estudo foram selecionados de dois bancos de dados sobre meningites do Hospital Couto Maia. O primeiro com informações de 97 pacientes com suspeita de meningoencefalite tuberculosa, que foi realizado para participação da Bahia em pesquisa operacional promovida pelo Ministério da Saúde em 1983. O segundo é um banco sobre meningites no qual foram coletados dados retrospectivos de 1700 pacientes internados com esta patologia entre jan/90 e dez/92 e, prospectivamente, de 809 pacientes durante o ano de 1993.

Destes bancos de dados foram selecionados os casos confirmados de meningoencefalite tuberculosa. Os critérios considerados para confirmação foram: pacientes que evoluíram para óbito e cuja necropsia evidenciou a presença de meningoencefalite tuberculosa; presença de BAAR no LCR, pelo método de Ziehi Nielsen; cultura positiva para BAAR no LCR; positividade de PCR no LCR.

Dos pacientes que preencheram esses critérios foram estudadas caracteristicas demográficas como sexo, idade e procedencia: se do interior ou capital do Estado. Foram analisados dados clínicos e laboratoriais como tempo de doença, febre, cefaléia, rigidez de nuca, alteraçð̌es neurológicas e sequelas à alta

\section{RESULTADOS}

Foram estudados 62 pacientes sendo $31(50 \%)$ do sexo masculino e 31 (50\%) do sexo feminino. As idades variaram de 2 meses a 50 anos; 24 pacientes (38,7\%) tinham idade igual ou inferior a 1 ano (Fig 1). Trinta e seis (58\%) dos casos eram procedentes da capital e $22(35,5 \%)$ do interior do Estado; em 4 (6,5\%) a procedência não foi registrada.

O tempo de doença variou de 0 (paciente chegou ao hospital no mesmo dia do início dos sintomas) a 90 dias, sendo a média 13 dias, o desvio padrão 14,57 e a mediana de 8 dias. Os sinais e sintomas mais importantes estão descritos na Tabela 1. 
Fig 1. Distribuição por faixa etária.

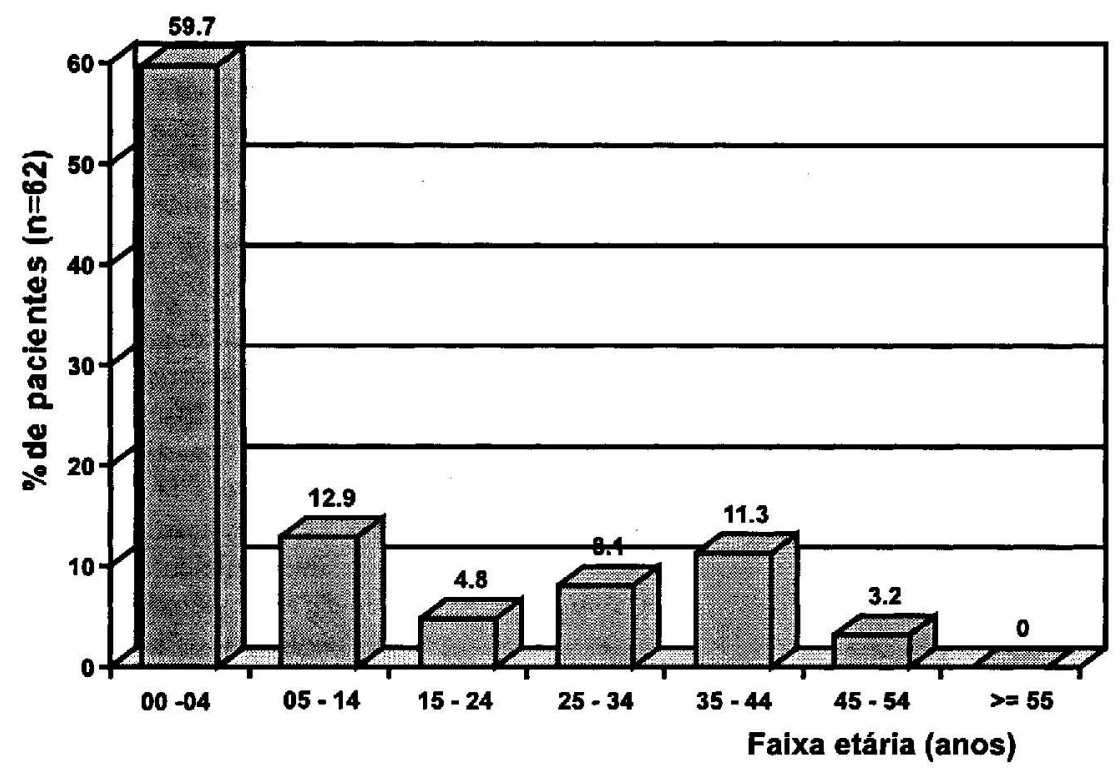

As caracteristicas do exame do LCR no que diz respeito a celularidade, dosagem de proteína e de glicose constam na Tabela 2 . Houve predominância foi de células linfomonocitárias em $\mathbf{4 2}$ $(68,9 \%)$ casos, e de polimorfonucleares em $13(21,3 \%)$; em $5(8,2 \%)$ ocorreu metade das células polimorfonucleares e a outra metade linfomonocitárias e em 1 caso a quantidade de LCR foi insuficiente para avaliação da celularidade.

Tabela 1. Sinais e sintomas.

\begin{tabular}{lll}
\hline Sinal ou sintoma & Presença (no. de casos) & $\%$ \\
\hline Febre & $52(60)$ & $86,7 \%$ \\
Cefaléia & $24(52)$ & $46,2 \%$ \\
Rigidez de nuca & $45(55)$ & $81,8 \%$ \\
Convulsåo & $26(57)$ & $45,6 \%$ \\
\hline
\end{tabular}

Tabela 2. Características do exame do LCR

\begin{tabular}{lcccc}
\hline Caracteristica & $\begin{array}{c}\text { Média } \pm \\
\text { desvio padrão }\end{array}$ & Mediana & Faixa & Anormalidade (\%) \\
\hline Celularidade & $406,46 \pm 366,31$ & 290 & 4 a 1549 & $100 \%$ \\
Proteina & $202,95 \pm 123,29$ & 200 & 30 a 500 & $93,4 \%$ \\
Glicose & $37,28 \pm 11,58$ & 40 & 20 a 70 & $78,7 \%$ \\
\hline
\end{tabular}


Tabela 3. Confirmação diagnóstica.

\begin{tabular}{lcc}
\hline Critério & $\mathrm{n}^{\circ}$ de pacientes & $\%$ \\
\hline BAAR positivo & 2 & 3,2 \\
BAAR positivo + necropsia & 1 & 1,6 \\
Cultura positiva & 23 & 37,1 \\
cultura positiva + PCR positivo & 4 & 6,5 \\
cultura positiva + necropsia & 8 & 12,9 \\
PCR positivo & 8 & 12,9 \\
necropsia & 16 & 25,8 \\
Total & 62 & 100 \\
\hline
\end{tabular}

A confirmação diagnóstica ocorreu em todos os casos, como pode ser visto na Tabela 3. Dos 62 pacientes, em 48 foi realizada a pesquisa de $B A A R$ no $L C R$, sendo positiva em $3(6,3 \%)$; a cultura de LCR foi realizada em 51 , sendo positiva em 35 (68,6\%). O PCR foi incluido como critério único de confirmação em 8 pacientes.

Dos 62 pacientes estudados, 31 (50\%) apresentaram déficits neurológicos e 40 $(64,5 \%)$ evoluíram para óbito.

\section{DISCUSSÃO}

Apesar dos avanços obtidos com o surgimento de novas técnicas diagnósticas na área de biologia molecular, principalmente no que se refere à identificação e caracterização dos processos infecciosos em geral, até o momento não houve avanço significativo para o estabelecimento precoce do diagnóstico de formas extrapulmonares de tuberculose. Algumas técnicas como ADA que surgiram com o objetivo de definir um mais acurado valor preditivo positivo para o diagnóstico de meningite tuberculosa mostraram-se posteriormente pouco especificas, fazendo com que voltasse a prevalecer a suspeita clínica associada a um padrão de $L C R$, poucas vezes confirmados com a pesquisa de BAAR e/ou cultura ${ }^{7,8}$. A utilização de técnicas para determinação do DNA, em que pese a sua alta sensibilidade, apresenta o inconveniente de ter alto custo o que dificulta a sua universalidade.

As dificuldades se acentuam quando comparamos alguns dados da nossa casuística com o observado por outros autores.

Em nosso estudo o BAAR foi positivo em 6,3\% dos casos, média de positividade menor que a observada na literatura, considerando ser esta série de casos confirmados ${ }^{21}$. A cultura foi positiva em $68,6 \%$, positividade maior que a observada em outros estudos; entretando deve-se levar em consideração que a positividade da cultura foi um dos critérios de inclusão utilizados ${ }^{2 !}$.

A maioria dos autores estabelece que o tempo dos sintomas antes do diagnóstico costuma variar de $10 \mathrm{a} 90$ dias $^{6,14}$ o que contrasta com os resultados do nosso estudo. Acreditamos, à semelhança de Davis e col., que estas divergências relacionam-se ao tipo de população estudada 4 . $O$ estudo realizado por estes últimos autores evidenciou um tempo médio de 13 dias de doença antes da hospitalização, média semelhante à nossa. Embora não tenha sido relatado pelo grupo de Davis o desvio padrão encontrado, observamos que as nossas casuísticas também são semelhantes quando analisamos a grande dispersão em torno da média em ambos os estudos.

Chamamos a atenção para que $35 \%$ dos nossos casos têm menos que 7 dias de sintomas antes da internação, havendo pacientes cujo padrão clínico e laboratorial inicial foram indistinguiveis daqueles observados nas assim chamadas meningites bacterianas agudas. Estas discrepâncias, como observado anteriormente, devem-se provavelmente às características da nossa populaça e ao fato de o maior número de casos ter ocorrido em crianças cuja sintomatologia é, na maioria das vezes, inespecifica ${ }^{21}$.

Em nossos pacientes não houve diferenças quanto ao sexo contrariando a totalidade da literatura pesquisada, a qual enfatiza a predominância em pacientes do sexo masculino, variando de 1,5 a 2,0 para $1^{13,18,20}$.

Nesta casuística a letalidade foi mais elevada do que a descrita na literatura estudada; entretanto, chamamos a atenção para que em 23 pacientes $(37,1 \%)$ o diagnóstico foi feito por necropsia ${ }^{1.19}$. 
Além do quadro clínico, o exame do LCR constitui-se no principal exame para o diagnóstico das meningites em geral. Em nossa casuística observamos pleocitose em todos os casos analisados. Em $62 \%$ dos pacientes o número de células permaneceu entre 100 e 600 . À semelhança de outros autores, observamos predomínio de linfócitos com aumento de proteinas e hipoglicorraquia na maioria dos pacientes ${ }^{6,7.10,16}$. No entanto, observa-se que $21,3 \%$ apresentavam predomínio de neutrófilos, concordando com outros estudos em que esta percentagem varia entre 20 e $25^{6}$. Estes dados reforçam a dificuldade em estabelecermos o diagnóstico de meningoencefalite tuberculosa baseados apenas em critérios isolados.

Neste estudo podemos observar que a uniðo de critérios clínicos e laboratoriais, realizados na maioria dos pacientes, poderá trazer boa confiabilidade diagnóstica, sendo necessária posterior avaliação do Valor Preditivo Positivo destas associações. Observamos, por exemplo, que a junção de febre, celularidade $>10<=1000$, com predominância de linfócitos e proteinorraquia $>60<$ $=500$ está presente em $60 \%$ dos pacientes estudados.

\section{REFERÊNCIAS}

1. Azambuja HCP, Picon PD, Rizzon CFC, Coutinho M. Meningite tuberculosa. In. Picon PD, Rizzon CFC, Ott WP (eds) Tuberculose : epidemiologia diagnóstico e tratamento em clínica e saúde pública. Rio de Janeiro: MEDSI, 1993;433-452.

2. Berman $S$, Kebel MA, Fouril PB, Strebel PM. Childhood tuberculosis and tuberculous meningitis: hight incidence rates in the Westem Cape of South Äfrica. Tubercle Lung Dis 1992;73:349-355.

3. Brasil. Ministério da Saúde. Controle da tuberculose: uma proposta de integrą̧ão ensino-serviço. Ed3 rev. Rio de Janeiro: CNTCNUTES, 1992.

4. Davis LE, Rastogi KR, Lambert CL, Skipper BJ. Tuberculous meningitis in the southwest United States: community study. Neurology 1993;43:1775-1778.

5. Frieden TR, Sterling T, Paplos-Mendez A, Kilbum JO, Cauthen GM, Dooleu SW. The emergence of drug - resistant tuberculosis in New York City. N Engl J Med,1993;328;521-526.

6. Haas DW, Prez RMD. Mycobacterium tuberculosis. In Gerald I, Mandell, E Bennett, R D (eds), Principles and practice of infectious diseases. New York: Churchill Livingstone, 1995:2213-2250.

7. Holdiness MR. Menagement of tuberculosis meningitis. Drugs 1990;39:224-232.

8. Kaneko K, Miyatake T, Tsuji S. Rapid diagnosis of tuberculous meningitis by polymerase chain reaction (PCR). Neurology 1990;49:1617-1618.

9. Liu PYF, Shi ZY, Lau YJ, Hu BS. Rapid diagnosis of tuberculous meningitis by a simplified nested amplification protocol. Neurology 1994;44:1161-1164.

10. Machado LR, Livramento JA, Bydlowiski SP, Bravo LM, Spina-França A. Polymerase chain reaction in the diagnosis of tuberculous meningitis: preliminary report. Arq Neuropsiquiatr 1994;52:445-446.

11. Martins TS, Medeiros CO, Gerhardt GF. Meningite tuberculosa (resultados de uma pesquisa operacional). J Bras Med, 1985;48:34-41.

12. Molavi A, Lefrock JL. Tuberculous meningitis. Med Clin N Am, 1985;69:315-331.

13. Nardy SMC. Brólio R, Belluomini M. Aspectos epidemiológicos da meningite tuberculosa em menores de 15 anos de idade na grande São Paulo, Brasil. 1982-1983. Rev Saúde Públ 1989;23:117-127.

14. Radhakrishnan VV, Mathai A. Detection of mycobacterial antigen in cerebrospinal fluid in patients with chronic meningitis by inhibition enzyme linked immunosbent assay. Indian J Med Res, 1990;91:355-359.

15. Shankar P, Manjunath N, Mohan K, Prasad K, Behari M, Shrinivas A, Ahuja GK. Rapid diagnosis of tuberculous meningitis by polymerase chain reaction. Lancet 1991;337:5-7.

16. Singh NK, Singh P, Tripathi K, Srivastava PK, Singh DS. Prognostic factors and sequelae of tuberculous meningitis in adults. JIndian M A, 1985;83:50-53.

17. Valenzuela MT, Crrasco E, Garcia $P$, Toro J. Analisis retrospectivo del prognóstico de la meingitis tuberculosa en Chile en relacion al diagnostico y al tratamiento. Enfermedades Respiratorias y Cirurgia Torácica 1988;4:124-132.

18. Vernal P, Param T, Casar C, Topelberg S. Menigitis Tuberculosa. Rev Chil Ped, 1986;57:255-259.

19. Waecker NJ, Connor JD. Central nervous system tuberculosis in children: a review of 30 cases. Ped Inf Dis J, 1990;9:539-543.

20. Watson DG, Shnier RC, Seale JP. Central system nervous tuberculosis in Australia: report of 22 cases. Med J Austr, 1993;158:408-413.

21. Zuger A, Lowy F. Tuberculosis of the central nervous system. In Sheld WM, Whithey RJ, Durack DT (eds). Infection of the central nervous system. New York: Raven Press, 1991:425-739. 